\title{
Financing adaptation
}

\author{
As climate change impacts are felt more and more around the world, adapting to change is becoming critical. \\ However, it is not clear whether actions being taken are effective in reducing risk and increasing resilience, and \\ access to financing is crucial.
}

F looding, record-breaking temperatures, drought and wildfire are impacting increasing numbers of people and ecosystems around the world. Attribution studies reveal the signature of anthropogenic climate change in these extreme events, and the physical science report from the IPCC released in September confirmed that human influence on the climate is unequivocal ${ }^{1}$. Mitigating GHG emissions under the Paris Agreement is thus of the utmost importance to limit the amount of additional warming and subsequent extreme events. However, it is also becoming clear that current pledges are not enough to limit warming to the Paris Agreement goals ${ }^{2}$.

This reality makes climate change adaptation increasingly urgent. For many regions, climate change impacts are not a distant future event; rather, they are being felt in the present, and adaptation efforts are ongoing. Moving forward efficiently relies on understanding implementation to date and on documenting past and current efforts and assessing their effectiveness. In this issue, Berrang-Ford et al. conduct a systematic assessment of the scientific literature on adaptation. Most adaptation actions documented were incremental, a response to hydrological changes, focussed on agriculture, and behavioural, implemented at the household or individual level. Very little evidence of risk reduction following adaptation exists in the academic literature. In the related News and Views, Johanna Nalau notes the importance to policymakers to know whether adaptation is happening and whether it is lowering risk and vulnerability to inform future policy decisions.

Adaptation and, in particular, adaptation that is transformative rather than incremental, requires resources and financing. COP15 in Copenhagen in 2009 set the goal of reaching climate finance contributions of US $\$ 100$ billion annually from developed countries by 2020 . Governments donated nearly US $\$ 80$ billion to climate finance in 2019 , and current estimates indicate that the US\$ $\$ 100$ billion goal for 2020 was not met ${ }^{3}$, although ambiguity in the guidelines for what counts as climate finance makes the actual contribution difficult to assess ${ }^{4}$. In light of this goal, the UK, host of COP26 this year, called for more funding from wealthy countries ahead of the

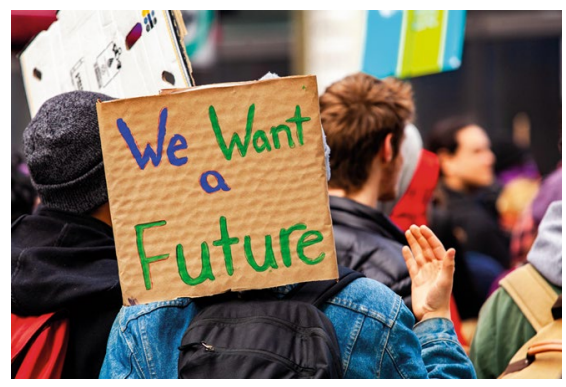

Credit: Valmedia / Alamy Stock Photo

conference, and the USA recently made a pledge to increase climate financing ${ }^{5}$.

Even if the finance goal is met, funds for adaptation are limited, as most support has historically been directed towards reducing emissions rather than to adaptation. For example, of the 2019 funding, only about $25 \%$ was used to support adaptation efforts. Moreover, much financing, particularly for adaptation, is in the form of loans that need to be repaid, which increases the burden of debt for developing countries ${ }^{6}$.

In addition to simply increasing funding, alternative mechanisms are needed to ensure that adaptation funding reaches the most vulnerable and supports equitable development. In a Comment, Thomas and Theokritoff highlight the fiscal problems facing small island developing states in the face of increasing extreme events under climate change and the COVID-19 pandemic, which have limited income from tourism and diverted funds from adaptation efforts. These financial constraints make climate action and adaptation difficult to implement. Thomas and Theokritoff argue for 'debt-for-climate swaps', which would entail debt forgiveness with the understanding that the payments would be used for action on climate change, thus lightening the burden on these countries and facilitating adaptation.

According to some estimates, US $\$ 90$ trillion in infrastructure investment is needed within the next 15 years to build resilience to climate change impacts. This number is high, but estimates also suggest that the economic benefits from such investment may be up to four times greater?
One of the greatest challenges is financing changes to energy infrastructure; recent work has shown that most remaining fossil fuel reserves must not be burned to achieve the Paris Agreement temperature goals.

Support for infrastructure is particularly needed in low-income and developing countries. In a Correspondence, Rabah Arezki points to challenges for climate progress and development in African countries, whose ability to attract investment is limited. However, Africa has great potential capacity for renewable energy, and investment aimed at overcoming these hurdles in a local context is critical, particularly for development in the energy and transport sectors.

Momentum around climate change adaptation does seem to be building, both in academic research ${ }^{9}$ and in political discourse. Adaptation and Finance are two of the key goals of COP26, and a new Collection highlights relevant research that supports these goals, as well as the topic of mitigation. Decisions made now regarding infrastructure, research and finance will affect how climate impacts play out in the future, and it is clear that immediate and ambitious action is needed - not only to lower emissions, but also to mitigate the impacts of climate change felt across the world now and by future generations.

Published online: 29 October 2021 https://doi.org/10.1038/s41558-021-01213-4

References

1. IPCC Climate Change 2021: The Physical Science Basis (eds Masson-Delmotte, V. et al.) (Cambridge Univ. Press, in the press).

2. Nationally Determined Contributions Under the Paris Agreement (UN, 2021); https://unfccc.int/sites/default/files/resource/ cma2021_08_adv_1.pdf

3. OECD Climate Finance Provided and Mobilised by Developed Countries: Aggregate Trends Updated with 2019 Data, Climate Finance and the USD 100 Billion Goal (OECD Publishing, 2021); https://doi.org/10.1787/03590fb7-en

4. Roberts, J. et al. Nat. Clim. Chang. 11, 180-182 (2021).

5. US Announces New Finance Pledge for Developing Country Climate Action World Resources Institute https://www.wri.org/ news/statement-us-announces-new-finance-pledge-developingcountry-climate-action (21 September 2021).

6. Climate Finance Shadow Report 2020 (Oxfam, 2020); https:// oxfamilibrary.openrepository.com/bitstream/handle/10546/ 621066/bp-climate-finance-shadow-report-2020-201020en.pdf

7. Hallegatte, S., Rentschler, J. \& Rozenberg, J. Lifelines: The Resilient Infrastructure Opportunity (World Bank, 2019).

8. Welsby, D., Price, J., Pye, S. \& Ekins, P. Nature 597, 230-234 (2021).

9. Nalau, J. \& Verrall, B. Clim. Risk Manag. 32, 100290 (2021). 